ISSN: 2146-3042

DOI: $10.25095 /$ mufad.877408

\title{
Yabancı Yatırımların Pay Piyasa Getirisine Etkisi: BRICS-T Ülkeleri Üzerine Ekonometrik Bir Analiz*
}

\author{
Erol KÖYCÜ** \\ Mustafa Mesut KAYALI***
}

\section{ÖZET}

Küreselleşme ile birlikte serbest ticaretin benimsenmesi, özellikle tasarruflarl yetersiz olan gelişmekte olan ülkeler için yabancı yatırımların önemini arttırmıştır. Yüksek getiri potansiyeline sahip ve cazip firsatları bünyesinde barındıran gelişmekte olan ülkeler, tasarruf açıklarını giderebilmek, ekonomik olarak büyüyebilmek, finansal piyasalarını geliştirebilmek ve belki de en önemlisini gelişimlerini tamamlayabilmek için yabancı kaynaklara ihtiyaç duymaktadırlar. Bu doğrultuda bu çalışmada, 2000-2018 döneminde BRICS-T ülkeleri olarak da ifade edilen, Brezilya, Rusya, Hindistan, Çin, Güney Afrika ülkelerine ve Türkiye’ye yapılan doğrudan yabancı yatırımlar ve portföy yatırımlarının pay piyasa getirisine etkisi, panel veri analiz yöntemi ile incelenmiştir. Yapılan analizler sonucunda; portföy yatırımları ile pay piyasa getirisi arasında anlamll ve pozitif yönde bir ilişki tespit edilirken, doğrudan yabancı yatırımlar ile pay piyasa getirisi arasında anlamlı bir ilişki tespit edilememiştir.

Anahtar Kelimeler: Yabancı Yatırımlar, Finansal Piyasalar, Panel Veri Analizi.

JEL Sinıflandirmasi: C23, C82, D53.

The Effect of Foreign Direct Investment and Portfolio Investment on Stock Market Returns: An Econometric Analysis on BRICS-T Countries

\section{ABSTRACT}

The adoption of free trade, combined with globalization, has increased the importance of foreign investment, especially for developing countries with insufficient savings. Developing countries with high yield potential and attractive opportunities need foreign resources to address their savings deficits, grow economically, develop their financial markets and, perhaps most importantly, complete their development. In this study, the effect of foreign direct investments and portfolio investments on stock market return in Brazil, Russia, India, China, South Africa and Turkey, also referred to as BRICS-T countries in the period 2000-2018 has been examined by panel regression analysis. As a result of the analysis, a significant and positive relationship between portfolio investments and stock market return has been determined, while a significant relationship between foreign direct investment and stock market return has not been determined.

Keywords: Foreign Investments, Financial Markets, Panel Data Analysis.

Jel Classification: C23, C82, D53.

\footnotetext{
* Makale Gönderim Tarihi: 09.02.2021, Makale Kabul Tarihi: 29.05.2021 , Makale Türü: Nicel Araştırma $\mathrm{Bu}$ makale, 'Doğrudan Yabancı Yatırımlar ve Portföy Yatırımlarının Pay Piyasa Getirisine Etkisi: BRICS-T Ülkeleri Üzerine Ekonometrik Bir Analiz’ başlıklı yüksek lisans tezinden türetilmiştir.

** Arş. Gör., Şırnak Üniversitesi, İktisadi ve İdari Bilimler Fakültesi, erol.koycu@hotmail.com, ORCIID: 00000001-8166-2185.

*** Prof. Dr., Dumlupınar Üniversitesi, İktisadi ve İdari Bilimler Fakültesi, mesutkayali@yahoo.com, ORCID: 0000-0001-9508-6270.
} 


\section{GíRiş}

1980’li yıllardan itibaren dünyanın büyük bölümünde ekonomik kısıtlamaların kaldırıldığı, sermaye hareketlerinin serbestleștiği ve serbest ticaret anlaşmalarının imzalandığı görülmektedir. Diğer bir ifadeyle; 1980'li yıllar küreselleşme kavramının önem kazandığ yıllar olarak ifade edilmektedir. Küreselleşme ile birlikte gelişmiş ülkelerdeki ihtiyaç fazlası yabancı sermaye akımlarının, aralarında Türkiye'nin de bulunduğu gelişmekte olan ülkelere hareketi hızlanmıştır. Yabancı sermaye akımlarının hızlanması ile birlikte hem ihtiyaç fazlası fon değerlendirilmiş olmakta hem de gelişmekte olan ülkelere fon sağlanmış olmaktadır.

Gelişmekte olan ülkelerin gerek kendi gelişimlerini sürdürebilmeleri gerekse dünyadaki gelişim ve değişimlerle rekabet edebilmeleri için karşılaştıkları önemli engellerden biri; sermaye yetersizliği sorunudur. $\mathrm{Bu}$ ülkelerde tasarrufların yetersizliği, yatırımların istenen düzeyde olmaması ve diş ticarette karşılaşılan açıklar gibi belli başı problemler, bu ülkeleri yabancı tasarruflara yönlendirmektedir. Gelişmekte olan ülkeler ihtiyaç duydukları bu tasarrufların finansmanı için dışarıdan yabancı sermaye akımı çekmeye çalışmaktadırlar. Bu tür yabancı sermaye akımları hedef ülkede doğrudan yabancı yatırımlar ve/veya portföy yatırımları olarak karşımıza çıkmaktadır.

Portföy yatırımları; hedef ülkede hisse ve tahvil piyasalarına yapılan yatırımları ifade etmektedir ve aynı zamanda literatürde sıcak para olarak da adlandırılmaktadır. Doğrudan yabancı yatırımlar ise; bir firmanın üretimini, kurulu olduğu kendi ülkesi dışındaki diğer ülkelere yayarak daha az maliyetli üretim yapmak amacıyla, hedef ülkelerde yeni üretim tesislerinin kurulmas1, mevcut üretim tesislerinin satın alınması veya mevcut yatırımlara ortak olunması şeklinde tanımlanabilir (Felek, 2016: 6).

Bu çalışmanın amacı; 2000-2018 dönemi için yabancı yatırımlar olarak da adlandırılan doğrudan yabancı yatırımlar ve portföy yatırımlarının, gelişmekte olan ülkeler topluluğu olarak ifade edilen BRICS ülkelerinin pay piyasa getirisine etkisini incelemektir. Ayrica çalışmanın Türkiye'de yapılıyor olmasından dolayı, çalışma kapsamı BRICS-T olarak genişletilmiştir. $\mathrm{Bu}$ amaç doğrultusunda mevcut çalışmada ilk olarak literatürde yer alan benzer çalışmalar araştırılmış ve literatür taraması başlığı altında sunulmuştur. Sonraki aşamada, metedoloji ve veri seti bölümünde, mevcut çalışmada kullanılacak yöntem ve formülizasyon bilgisine değinilmiş ve devamında çalışmanın bağımlı-bağımsız değişkenlerinden ve veri setinden bahsedilmiştir. Çalışmanın yöntem ve veri setinin açıklanmasından sonra, uygulanacak testlere geçilmiş ve elde edilen bulgular anlaşılır bir biçimde olmasına özen gösterilerek, ampirik bulgular başlığı altında sunulmuştur. Mevcut çalışmanın son bölümü olan sonuç ve öneriler kısmında ise, çalışmada elde edilen sonuçlara ve ilgili taraflar için önerilere yer verilmiştir.

Literatürde yer alan ilgili diğer çalışmalar incelendiğinde, çalışmaların çoğunlukla yabancı yatırımlar ile ekonomik büyüme arasındaki ilişkiye odaklandığı görülmektedir. $\mathrm{Bu}$ çalışmanın, yabancı yatırımlar ile pay piyasa getirisini BRICS-T ülkeleri özelinde ele alması bakımından literatüre katkı sunacağı ve alan yazınına özgünlük katacağı düşünülmektedir. Ayrıca literatürde, BRICS-T ülkeleri özelinde yabancı yatırımların pay piyasa getirisine etkisi daha önce incelenmediği görülmektedir. Bu bağlamda çalışmanın, öncü çalışmalardan biri 
olmakla birlikte, literatüre farklı bir bakış açısı kazandırmasından dolayı önem taşıdığı düşünülmektedir.

\section{LITERATÜR TARAMASI}

Doğrudan yabancı yatırımlar ve portföy yatırımları ile ilgili literatür çalışmaları incelendiğinde, çalışmalarının genellikle benzer konular üzerinde yoğunlaştığı görülmektedir. Genel kabul görmüş sonuç ise, doğrudan yabancı yatırımların ekonomik büyüme başta olmak üzere hedef ülkeye birçok avantaj sağladığı, bununla birlikte portföy yatırımlarının ise çalışmada kullanılan değişkenlere ve veri setine bağlı olarak farklı şekillerde hedef ülkeye etkisinin olduğu yönündedir. Bahsi geçen literatür çalışmaları, aşağıdaki tablo 1 'de sunulmuştur.

Tablo 1. Literatür Tablosu

\begin{tabular}{|c|c|c|c|c|c|}
\hline Yazar & & Yll & Kapsam & Amaç & Bulgular \\
\hline Das & & 2000 & $\begin{array}{l}\text { 1990-1998 } \\
\text { dönemi, } \\
\text { gelişmekte olan } \\
\text { ekonomiler }\end{array}$ & $\begin{array}{l}\text { Portföy yatırımlarının } \\
\text { olumlu ve olumsuz } \\
\text { yönleri }\end{array}$ & $\begin{array}{l}\text { Portföy yatırımları finansal } \\
\text { piyasalarda volatiliteyi arttırmakta ve } \\
\text { ülkelerin finansal piyasaları arasındaki } \\
\text { bulaşıcı etkiye katkı sağlamaktadır. }\end{array}$ \\
\hline Errunza & & 2001 & $\begin{array}{l}\text { 1981-1996 } \\
\text { döneminde } \\
\text { gelişmekte } \\
\text { ülkeler }\end{array}$ & $\begin{array}{l}\text { Portföy yatırımlarının } \\
\text { olumlu ve olumsuz } \\
\text { yönleri }\end{array}$ & $\begin{array}{l}\text { Portföy yatırımları finansal piyasaların } \\
\text { gelişimi için büyük öneme sahiptir. } \\
\text { Yapısal reformlarla portföy yatırımları } \\
\text { çekilebilir. }\end{array}$ \\
\hline Kim ve Wei & & 2002 & $\begin{array}{l}\text { 1996-1998 } \\
\text { dönemi Güney } \\
\text { Kore pay piyasası }\end{array}$ & $\begin{array}{l}\text { Yabancı } \\
\text { yatırımcıların } \\
\text { davranışlarının } \\
\text { analizi }\end{array}$ & $\begin{array}{l}\text { Yabancı yatırımcıları daha şeffaf bir } \\
\text { şekilde bilgilendirerek, portföy } \\
\text { yatırımları arttırılabilir. }\end{array}$ \\
\hline $\begin{array}{l}\text { Hermes } \\
\text { Lensink }\end{array}$ & ve & 2003 & $\begin{array}{l}\text { 1970-1995 } \\
\text { dönemi için } 67 \\
\text { ülke }\end{array}$ & $\begin{array}{l}\text { Doğrudan } \quad \text { yabanci } \\
\text { yatırımlar ile finansal } \\
\text { piyasalar arasındaki } \\
\text { ilişki }\end{array}$ & $\begin{array}{l}\text { Finansal piyasaların gelişmesi, hem } \\
\text { doğrudan yabancı yatırımlara hem de } \\
\text { ekonomik büyümeye olumlu ve pozitif } \\
\text { yönde bir etkisi vardır. }\end{array}$ \\
\hline
\end{tabular}

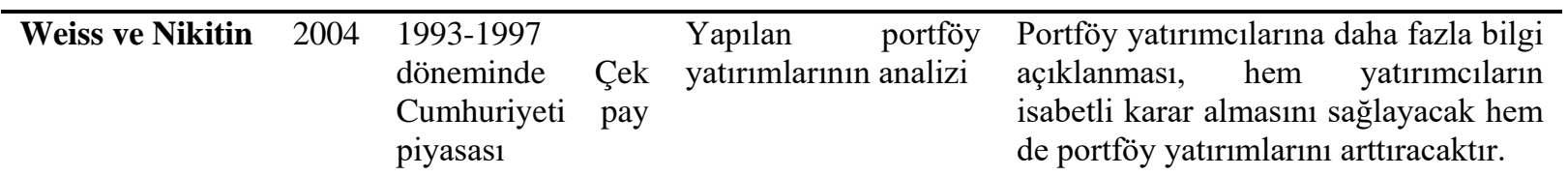

\begin{tabular}{|c|c|c|c|c|}
\hline $\begin{array}{l}\text { Somuncu } \\
\text { Karan }\end{array}$ & ve 2005 & $\begin{array}{l}2001-2004 \\
\text { dönemi için Borsa } \\
\text { İstanbul pay } \\
\text { piyasas1 }\end{array}$ & $\begin{array}{l}2001 \text { krizinde ve kriz } \\
\text { sonrasında portföy } \\
\text { yatırımlarının seyri }\end{array}$ & $\begin{array}{l}\text { Hem kriz döneminde hem de kriz } \\
\text { sonrası dönemde yerli ve yabancı } \\
\text { yatırımcılar, yatırımlarında ihtiyatlı } \\
\text { davranmışlardır. Bununla birlikte kriz } \\
\text { döneminde ve sonrasında yabancı } \\
\text { portföy yatırımları artarak devam } \\
\text { etmiştir. }\end{array}$ \\
\hline
\end{tabular}




\begin{tabular}{|c|c|c|c|c|}
\hline Guerin & 2006 & 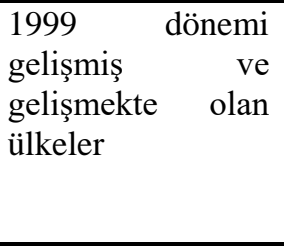 & $\begin{array}{lr}\text { Coğrafi } & \text { özelliklerin } \\
\text { yabancı } & \text { yatırımlar } \\
\text { üzerindeki etkisi }\end{array}$ & $\begin{array}{l}\text { Coğrafi özellikler hem doğrudan } \\
\text { yabancı yatırımlara hem de portföy } \\
\text { yatırımlarına olumlu bir etkisi vardır. } \\
\text { Bununla birlikte gelişmekte olan } \\
\text { ülkeler daha fazla yabancı yatırım } \\
\text { çekmektedir. }\end{array}$ \\
\hline $\begin{array}{l}\text { Poshakwale ve } \\
\text { Thapa }\end{array}$ & 2007 & $\begin{array}{l}\text { 2001-2007 } \\
\text { döneminde } \\
\text { Amerika, İngiltere } \\
\text { ve Hindistan pay } \\
\text { piyasası }\end{array}$ & $\begin{array}{l}\text { Portföy yatırımlarının } \\
\text { pay piyasa } \\
\text { getirilerine etkisi }\end{array}$ & $\begin{array}{l}\text { Hindistan pay piyasası Amerika ve } \\
\text { İngiltere pay piyasalarından } \\
\text { etkilenmektedir ve portföy yatırımlar } \\
\text { hem uzun hem de kısa vadede } \\
\text { Hindistan pay piyasasını olumlu } \\
\text { etkilemektedir. }\end{array}$ \\
\hline $\begin{array}{ll}\text { Adam } & \text { ve } \\
\text { Tweneboah } & \end{array}$ & 2008 & $\begin{array}{l}\text { 1991-2006 } \\
\text { dönemi için Gana } \\
\text { pay piyasası }\end{array}$ & \begin{tabular}{lr} 
Doğrudan & \multicolumn{2}{c}{ yabancı } \\
yatırımlar & ile pay \\
piyasası & arasındaki \\
ilişki &
\end{tabular} & $\begin{array}{l}\text { Doğrudan yabancı yatırımlar uzun } \\
\text { vadede pay piyasasını pozitif yönde } \\
\text { etkilemektedir. }\end{array}$ \\
\hline
\end{tabular}

\begin{tabular}{|c|c|c|c|c|}
\hline Vita ve Kyaw & 2009 & $\begin{array}{l}\text { 1985-2020 } \\
\text { dönemi } \\
\text { gelişmekte } \\
\text { ülke }\end{array}$ & $\begin{array}{lr}\text { Yabancı } & \text { yatırımların } \\
\text { hedef } & \text { ülkelere } \\
\text { faydaları } & \end{array}$ & $\begin{array}{l}\text { Doğrudan yabancı yatırımlar ve } \\
\text { portföy yatırımları, ülkelerin } \\
\text { ekonomik olarak büyümelerini pozitif } \\
\text { yönde etkilemektedir. }\end{array}$ \\
\hline $\begin{array}{l}\text { Al-Halalmeh ve } \\
\text { Sayah }\end{array}$ & 2010 & $\begin{array}{l}\text { 2006-2009 } \\
\text { döneminde } \\
\text { Amman } \\
\text { piyasas1 }\end{array}$ & $\begin{array}{l}\text { Doğrudan yabancı } \\
\text { yatırımların } \\
\text { piyasasına etkisi }\end{array}$ & $\begin{array}{l}\text { Doğrudan yabancı yatırımlar, pay } \\
\text { piyasasını } \\
\text { etkilemektedir. }\end{array}$ \\
\hline Ara & 2011 & 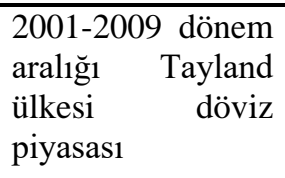 & $\begin{array}{lr}\text { Yabancı } & \text { yatırımların } \\
\text { döviz } & \text { piyasasına } \\
\text { etkisi } & \end{array}$ & $\begin{array}{l}\text { Döviz kurunun seyri doğrudan yabancı } \\
\text { yatırımları ve portföy yatırımlarını } \\
\text { etkilemektedir. }\end{array}$ \\
\hline
\end{tabular}

\begin{tabular}{|c|c|c|c|c|}
\hline Ananyochukwu & 2012 & $\begin{array}{l}\text { 1990-2009 } \\
\text { dönemi Nijerya } \\
\text { pay piyasası }\end{array}$ & $\begin{array}{l}\text { Portföy yatırımlarının } \\
\text { pay piyasa getirisine } \\
\text { etkisi }\end{array}$ & $\begin{array}{l}\text { Portföy yatırımlarının pay piyasa } \\
\text { getirisi üzerinde önemli ve pozitif } \\
\text { yönde bir etkisi vardır. }\end{array}$ \\
\hline Gupta vd. & 2013 & $\begin{array}{l}2001-2012 \\
\text { döneminde } \\
\text { Hindistan } \\
\text { piyasası }\end{array}$ & $\begin{array}{l}\text { Yabanci yatırımların } \\
\text { pay piyasa } \\
\text { volatilitesine etkisi }\end{array}$ & $\begin{array}{l}\text { Doğrudan yabancı yatırımlar ve } \\
\text { portföy yatırımlarının artması, pay } \\
\text { piyasası volatilitesini arttırmaktadır. } \\
\text { Yabancı yatırımlar ile pay piyasa } \\
\text { arasında güçlü korelasyon vardır. }\end{array}$ \\
\hline Halale & 2014 & $\begin{array}{l}\text { 2003-2013 } \\
\text { dönemi } \\
\text { Hindistan } \\
\text { piyasas1 }\end{array}$ & $\begin{array}{l}\text { Portföy yatırımlarının } \\
\text { pay piyasa getirisine } \\
\text { etkisi }\end{array}$ & $\begin{array}{l}\text { Portföy yatırımları, pay piyasa } \\
\text { getirisini olumlu yönde etkilemektedir. }\end{array}$ \\
\hline $\begin{array}{l}\text { Bhatia } \\
\text { Kishor }\end{array}$ & 2015 & $\begin{array}{l}2005-2015 \\
\text { döneminde } \\
\text { BRICS ülkeleri } \\
\text { pay piyasaları }\end{array}$ & $\begin{array}{l}\text { Portföy yatırımları ile } \\
\text { pay piyasası } \\
\text { arasındaki ilişki }\end{array}$ & $\begin{array}{l}\text { Portföy yatırımları, Brezilya, } \\
\text { Hindistan ve Güney Afrika ülkeleri } \\
\text { pay piyasalarını olumlu etkilerken, } \\
\text { Rusya ve Çin ülkeleri pay piyasalarını } \\
\text { sınırlı pozitif etkilemektedir. }\end{array}$ \\
\hline Idenyi vd. & 2016 & $\begin{array}{l}\text { 1984-2015 } \\
\text { dönemi Nijerya } \\
\text { pay piyasası }\end{array}$ & $\begin{array}{lr}\text { Doğrudan } & \text { yabanc1 } \\
\text { yatırımların } & \text { pay } \\
\text { piyasası } & \text { gelişimine } \\
\text { etkisi } & \end{array}$ & $\begin{array}{l}\text { Doğrudan yabancı yatırımların, pay } \\
\text { piyasası gelişimine bir etkisi yoktur. }\end{array}$ \\
\hline
\end{tabular}




\begin{tabular}{|c|c|c|c|c|c|c|}
\hline $\begin{array}{l}\text { Raghavan } \\
\text { Selvam }\end{array}$ & ve & 2017 & $\begin{array}{l}\text { 2014-2016 dön } \\
\text { aralığında } \\
\text { Hindistan } \\
\text { piyasası }\end{array}$ & nem & $\begin{array}{l}\text { Portföy yatırımlarının } \\
\text { pay piyasasına etkisi }\end{array}$ & $\begin{array}{l}\text { Portföy yatırımları ile birlikte } \\
\text { piyasalarda bir yükseliş olduğu } \\
\text { dolayısıyla portföy yatırımları hem } \\
\text { piyasaları hem de yatırımcı karlarını } \\
\text { olumlu yönde etkilemektedir. }\end{array}$ \\
\hline Iriobe vd. & & 2018 & $\begin{array}{l}2007-2017 \\
\text { dönemi } \\
\text { Nijerya } \\
\text { piyasas1 }\end{array}$ & $\begin{array}{l}\text { için } \\
\text { pay }\end{array}$ & $\begin{array}{l}\text { Portföy yatırımları ile } \\
\text { pay piyasası } \\
\text { arasındaki ilişki }\end{array}$ & $\begin{array}{l}\text { Portföy yatırımları, pay piyasasını } \\
\text { pozitif yönde etkilemektedir. }\end{array}$ \\
\hline Ege vd. & & 2019 & $\begin{array}{l}\text { 2005-2016 } \\
\text { dönemi } \\
\text { ülkeleri }\end{array}$ & E7 & $\begin{array}{l}\text { Yabancı yatırımların } \\
\text { pay piyasa getirisine } \\
\text { etkisi }\end{array}$ & $\begin{array}{l}\text { E7 ülkeleri pay piyasa getirileri ile } \\
\text { portföy yatırımları arasında pozitif } \\
\text { yönlü bir ilişki tespit edilirken, E7 } \\
\text { ülkeleri pay piyasa getirileri ile } \\
\text { doğrudan yabancı yatırımlar arasında } \\
\text { bir ilişki tespit edilememiştir. }\end{array}$ \\
\hline Islam vd. & & 2020 & $\begin{array}{l}\text { 1999-2017 } \\
\text { dönemi } 79 \text { ülke }\end{array}$ & & $\begin{array}{l}\text { Doğrudan yabancı } \\
\text { yatırımlar ve finansal } \\
\text { piyasaların gelişimi } \\
\text { arasındaki ilişki }\end{array}$ & $\begin{array}{l}\text { Ülkelerin finansal piyasalarının } \\
\text { gelişimi, doğrudan yabancı yatırımları } \\
\text { çekmektedir. }\end{array}$ \\
\hline
\end{tabular}

Yukarıda yer alan literatür çalışmalarından da görüleceği üzere, portföy yatırımları genel olarak finansal piyasaları olumlu yönde etkilerken, doğrudan yabancı yatırımların finansal piyasalara etkisi çalışmadan çalışmaya değişiklik göstermektedir. Finansal piyasalara yatırım yapan gerçek veya tüzel yatırımcılar için finansal piyasaların getirileri önemli bir konudur. Bu doğrultuda, yabancı yatırımların pay piyasa getirisine etkisinin incelenmesi, yatırımcılara faydalı bilgiler sunacaktır.

\section{METODOLOJI, VERI SETI VE HIPOTEZLER}

Bu çalışmada, doğrudan yabancı yatırımlar ile portföy yatıımlarının BRICS-T ülkeleri pay piyasa getirilerine etkisi incelenmiştir. Bu bağlamda, 2000-2018 dönemine ilişkin yıllık bazda doğrudan yabancı yatırımlar ve portföy yatırımları verileri Dünya Bankası resmi sitesinden (www.worldbank.org, 2020) alınmıştır. Aynı dönem BRICS-T ülkeleri pay piyasası kapanış değerleri ise www.investing.com veri tabanından sağlanmıştır. Pay piyasaları kapanış değerleri üzerinden, aşağıdaki formül yardımıyla piyasa getirileri hesaplanmıştır.

$$
\mathrm{R}_{\mathrm{t}}=\ln \left(\frac{P_{t}}{P_{t-1}}\right)
$$

Sonraki aşamada araştırmada kullanılan değişkenler doğrultusunda panel regresyon modeli oluşturulmuştur. Bu model, yatay kesit verilerinden ve zaman serisi verilerinden türetilmiştir. Çalışmada kapsam olarak BRICS-T gibi belirli bir topluluğu ifade eden ülkeler grubunun seçilmesi ve kısıt olarak ise 2000-2018 döneminin seçilmesi nedeniyle regresyon modelinde sabit etkiler modeli tercih edilmiştir. Bu model aşağıda verilmiştir;

$$
Y_{\text {it }}=\beta_{0 i t}+\beta_{1} X_{1 i t}+\beta_{2} X_{2 i t}+\varepsilon_{i t}+\lambda_{\text {it }}
$$

Yukarıdaki verilen modelin oluşturulmasında bağımlı değişken olarak pay piyasası getirisi esas alınmıştır. Bağımsız değişken olarak ise doğrudan yabancı yatırımlar ve portföy yatırımları esas alınmıştır. Modelde; Y her bir ülke (i) ve yıllık dönemler (t) için pay piyasa 
getirisini, X1: doğrudan yabanc1 yatırımlar, X2: portföy yatırımlarını ifade ederken, $\beta$ açıklayıcı değişkenlerin eğim katsayısını ve $\varepsilon_{\text {it }}$ ise hata terimini ifade etmektedir.

Metedoloji açıklamasından sonra, çalışmanın veri setinden de bahsedecek olursak, ilk olarak BRICS-T ülkelerinin önemli pay piyasaları investing.com sitesinden seçilmiştir. Bunlar;

Tablo 2. BRICS-T Ülkeleri Pay Piyasaları

\begin{tabular}{ll}
\hline \multicolumn{1}{c}{ Ülke } & \multicolumn{1}{c}{ Pay Piyasası } \\
\hline Brezilya & Bovespa Index \\
\hline Rusya & Imoex \\
\hline Hindistan & Nifty-50 Index \\
\hline Çin Halk Cumhuriyeti & Shangai Composite Index \\
\hline Güney Afrika & Jalsh Index \\
\hline Türkiye & Bist-100 \\
\hline
\end{tabular}

Not: www.investing.com, 02.03.2020.

Çalışmanın bağımlı bağımsız değişkenleri ile, bu değişkenlerin hesaplanmasında kullanılan yöntem aşağıdaki tabloda verilmiştir;

Tablo 3. Bağımlı ve Bağımsız Değişkenlere İlişkin Tanımlar

\begin{tabular}{cccc}
\hline & Değişken & Tanım & Açıklama \\
\hline $\begin{array}{c}\text { Bağımlı } \\
\text { Değişken }\end{array}$ & PAYGETYUZ & $\begin{array}{c}\text { Pay Piyasa } \\
\text { Getirisi }\end{array}$ & $\begin{array}{c}\text { (İlgili dönemin kapanış fiyatı - Bir önceki } \\
\text { dönemin kapanış fiyatı) / Bir önceki } \\
\text { dönemin kapanış fiyatı [Yüzdesel Değişim] }\end{array}$ \\
\hline Bağımsız & DOGYAT & $\begin{array}{c}\text { Doğrudan } \\
\text { Yabancı } \\
\text { Yeğişken }\end{array}$ & $\begin{array}{c}\text { (İlgili dönemin yatırım tutarı - Bir önceki } \\
\text { dönemin yatırım tutarı) / Bir önceki } \\
\text { dönemin yatırım tutarı [Yüzdesel Değişim] }\end{array}$ \\
\cline { 2 - 4 } & PORTYAT & $\begin{array}{c}\text { Portföy } \\
\text { Yatırımları }\end{array}$ & $\begin{array}{c}\text { (İlgili dönemin yatırım tutarı - Bir önceki } \\
\text { dönemin yatırım tutarı) / Bir önceki } \\
\text { dönemin yatırım tutarı [Yüzdesel Değişim] }\end{array}$ \\
\hline
\end{tabular}

Yukarıdaki tablodan da görüleceği üzere, mevcut çalışmanın bağımlı değişkeni 'PAYGETYUZ' olarak ifade edilirken, bağımsız değişkenlerden ilki olan doğrudan yabancı yatırımlar 'DOGYAT', bir diğer bağımsız değişken olan portföy yatırımları ise 'PORTYAT' olarak ifade edilmektedir. Yukarıda da değinildiği üzere, ilk olarak pay piyasası kapanış değerleri üzerinden pay piyasası logaritmik getirileri hesaplanmış, sonraki aşamada çalışmanın tutarlı sonuçlar vermesi için tüm değişkenlerin yüzdesel getirileri hesaplanarak, bir veri seti oluşturulmuştur. Çalışmaya elde edilen bulgular kısmı ile devam edilmişstir.

Çalışmada kullanılan bağımsız değişkenler dikkate alınarak, iki farklı hipotez oluşturulmuştur. Bu hipotezler; 
Hipotez 1 için;

Ho: Doğrudan yabancı yatırımlar ile pay piyasası getirisi arasında anlamlı bir ilişki yoktur. vardir.

$\mathrm{H}_{1}$ : Doğrudan yabancı yatırımlar ile pay piyasası getirisi arasında anlamlı bir ilişki

Hipotez 2 için;

$\mathrm{H}_{0}$ : Portföy yatırımları ile pay piyasası getirisi arasında anlamlı bir ilişki yoktur.

$\mathrm{H}_{1}$ : Portföy yatırımları ile pay piyasası getirisi arasında anlamlı bir ilişki vardır.

\section{AMPÍRIK BULGULAR}

Çalışmanın bu bölümünde analiz test sonuçları sunulacaktır. Çalışmada kullanılan değişkenler hakkında daha ayrıntılı bilgiye sahip olmak için ilk olarak tanımlayıcı istatistikler sunulmuştur.

Tablo 4. Tanımlayıcı İstatistikler

\begin{tabular}{lccc}
\hline & PAYGETYUZ & DOGYAT & PORTYAT \\
\hline Ortalama & 0.167676 & 0.167324 & -0.446511 \\
\hline Medyan & 0.107806 & 0.095037 & -0.472588 \\
\hline Maksimum & 1.284779 & 2.601795 & 7.036002 \\
\hline Minimum & -0.675188 & -0.904434 & -7.483900 \\
\hline Standart Sapma & 0.374362 & 0.600602 & 1.816358 \\
\hline Çarpıklık & 0.556941 & 1.525120 & -0.045892 \\
\hline Basıklık & 3.449643 & 6.548564 & 8.110379 \\
\hline Jarque-Bera & 6.493102 & 98.53319 & 117.5598 \\
\hline Olasilık & 0.038908 & 0.000000 & 0.000000 \\
\hline Gözlem & 108 & 108 & 108 \\
\hline
\end{tabular}

Tablo incelendiğinde bağımlı değişken olan PAYGETYUZ değişkenine ait ortalama değerin 0.167 olduğu, bağımsız değişkenler olan DOGYAT ve PORTYAT değişkenlerinin ortalamasının ise sırasıyla 0.167 ve -0.446 olduğu görülmektedir. Bu sonuçlara göre, 20002018 dönemi arasında BRICS-T ülkelerinde ortalama getiri \%16, ortalama doğrudan yabancı yatırım \%16 ve ortalama portföy yatırımlarının -\%44 olduğu söylenebilir. Bunun dışında standart sapma verileri incelendiğinde; portföy yatırımlarında 1.816358 katsayı değeri ile oynaklığın daha fazla olduğu ve bunu sirasıyla 0.600602 katsayı değeri ile doğrudan yabancı yatırımlar ve 0.374362 katsayı değeri ile pay piyasa getirisinin izlediği söylenebilir. Normal dağılım göstergesi olan çarpıklık ve basıklık değerleri incelendiğinde tüm değişkenlerin normal dağılmadıkları söylenebilir. Jargue-Bera olasılık değeri bu durumu destekler niteliktedir. Çünkü Jargue-Bera testinin yokluk hipotezi; ' $\mathrm{H}_{0}$ : Seriler normal dağılmaktadır' 
tezini savunmaktadır. Analiz sonucunda Jargue-Bera olasılık değerlerimiz kritik değer olan 0.05 'ten küçük olduğu için hipotez reddedilmektedir yani seriler normal dağılmamaktadır. Sonraki aşamada model bazında normal dağılım varsayımı Histogram grafiği ile incelenmiş, sonuçlar aşağıda sunulmuştur;

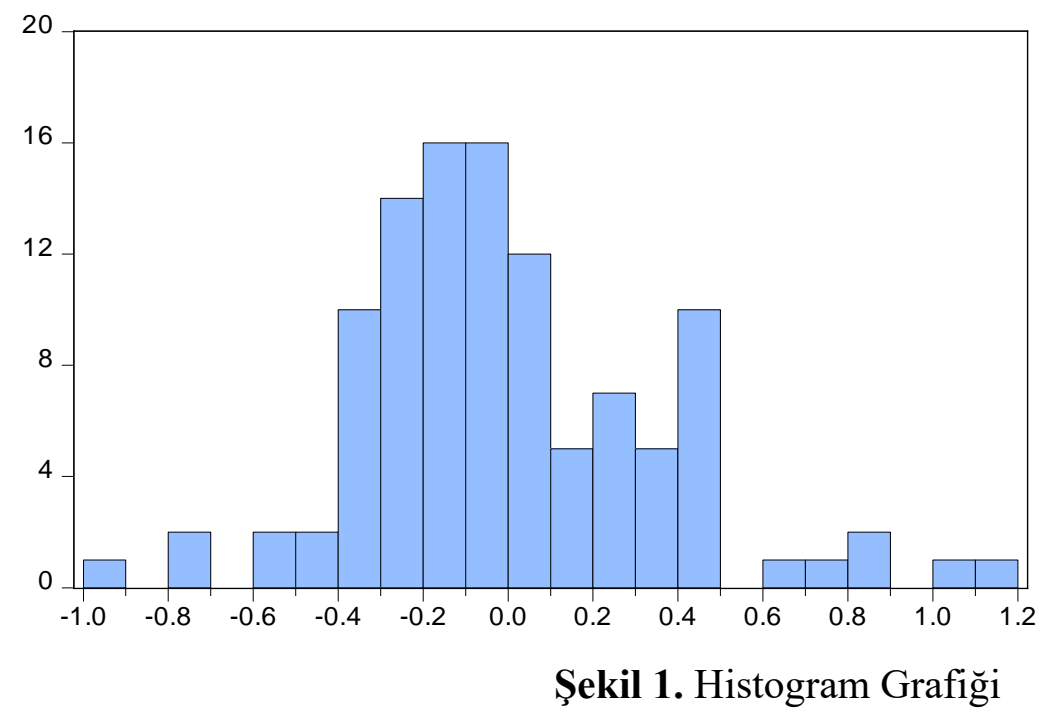

\begin{tabular}{|lc}
\hline \multicolumn{2}{|l|}{ Series: Residuals } \\
Sample 1 108 \\
Observations 108 \\
Mean & $2.62 \mathrm{e}-17$ \\
Median & -0.053909 \\
Maximum & 1.114782 \\
Minimum & -0.994849 \\
Std. Dev. & 0.355007 \\
Skewness & 0.526411 \\
Kurtosis & 3.912487 \\
& \\
Jarque-Bera & 8.734792 \\
Probability & 0.012684
\end{tabular}

Model bazında normal dağılım varsayımı için oluşturulan Histogram grafiği incelendiğinde, Jargue-Bera olasılık değeri, kritik değer olan 0.05 'ten küçük olduğu için temel hipotezin burada da reddedildiği ve normal dağılımın olmadığı görülmektedir.

Panel veri regresyon analizi çalışmalarında güvenilir sonuçlar elde edilebilmesi için temel varsayım; çoklu doğrusal bağlantı (dışsallık) ve içsellik sorunlarının olmamasıdır. Çoklu doğrusal bağlantı sorunu, bağımsız değişkenler arasındaki yüksek korelasyon (\%70 ve üzeri) ilişkisi sonucu ortaya çıkmaktayken, içsellik sorunu ise bağımlı ve bağımsız değişken arasındaki yüksek korelasyon (\%70 ve üzeri) ilişkisi sonucu ortaya çıkmaktadır. Çoklu doğrusal bağlantı sorunu serpilme diyagramı ile gözlenmekte, korelasyon analizi ve VIF testi ile tespit edilebilmektedir. Çoklu doğrusal bağlantı sorununu gözlemlemek için yapılan serpilme diyagramı aşağıda verilmiştir; 


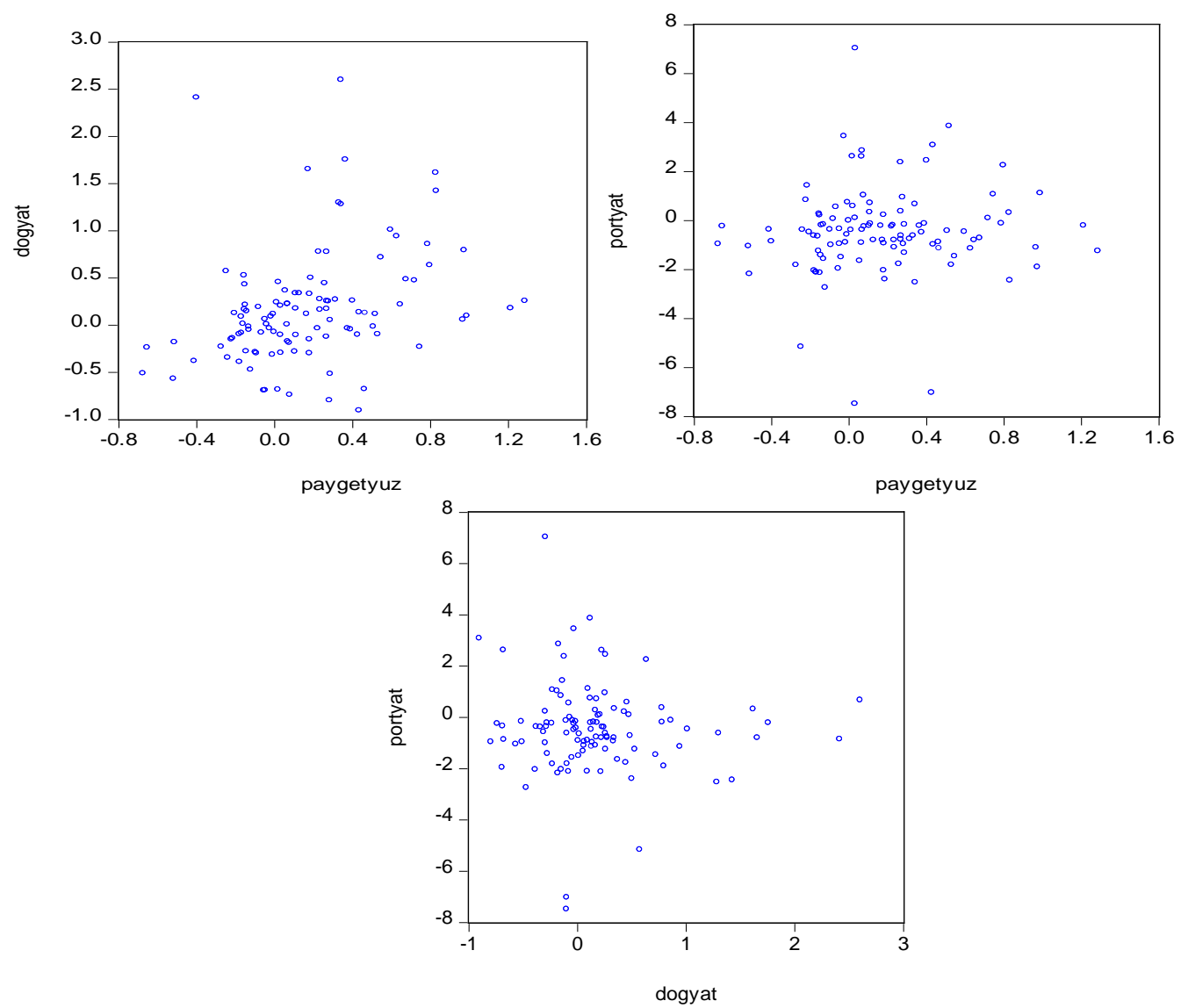

Şekil 2. Serpilme Diyagramı

Grafiklerde değişkenler kendi içerisinde karşılaştırılmıştır. Şekillerde yer alan sonuçlar incelendiğinde verilerin dağınık bir dağılım gösterdiği görülmektedir. Dolayısıyla pozitif ya da negatif bir dağılım seyri görülmemektedir. Şekillerin tümü için doğrusal ilişki yoktur yorumu yapılabilir. Serpilme diyagramından sonra, değişkenler arasındaki korelasyon katsayılarına bakılmıştır.

Tablo 5. Korelasyon Analizi

\begin{tabular}{lccc}
\hline $\begin{array}{l}\text { Correlation } \\
\text { t-Statistic } \\
\text { Olasilik }\end{array}$ & PAYGETYUZ & DOGYAT & PORTYAT \\
\hline \multicolumn{1}{c}{ PAYGETYUZ } & 1.000000 & & \\
& ----- & & \\
\hline \multirow{2}{*}{ DOGYAT } & ---- & 1.000000 & \\
& 0.396557 & ----- & 1.000000 \\
\hline \multirow{2}{*}{ PORTYAT } & 4.447450 & ---- & ----- \\
\hline
\end{tabular}

Korelasyon analizinde, serilerin normal dağılmamasından dolayı spearman korelasyon tersti uygulanmıştır. Yukarıda yer alan analiz sonuçları incelendiğinde, bağımsız değişkenler 
arasındaki korelasyon katsayısının -\%3 olduğu görülmektedir. Elde edilen bu oran, serpilme diyagramında tespit edilen çoklu doğrusal bağlantı sorunu yoktur tezini destekler niteliktedir. Korelasyon analizinde tespit edilecek bir diğer varsayım ise içsellik sorunudur. Bağımlı değişken ile bağımsız değişkenler arasındaki korelasyon ilişkisi incelendiğinde, en yüksek korelasyon katsayısının doğrudan yabancı yatırımlar ile pay piyasa getirisi arasında olduğu, oranın da yaklaşık \%39 gibi bir değer aldığı görülmektedir. Buradan hareketle, mevcut çalışmada içsellik sorununun da olmadığı söylenebilir. Dışsallık sorunu tespiti için bir diğer varsayımsal test VIF (Variance Inflation Factor) testidir.

Tablo 6. VIF Testi

\begin{tabular}{cccc}
\hline Değişkenler & $\begin{array}{c}\text { Katsayı } \\
\text { Varyansı }\end{array}$ & $\begin{array}{c}\text { Uncentered } \\
\text { VIF }\end{array}$ & $\begin{array}{c}\text { Centered } \\
\text { VIF }\end{array}$ \\
\hline & & & \\
DOGYAT & 0.003344 & 1.083855 & 1.005114 \\
PORTYAT & 0.000366 & 1.066422 & 1.005114 \\
C & 0.001344 & 1.130137 & NA \\
\hline
\end{tabular}

Varyans şişirme testi olarak da ifade edilen VIF testine göre, merkezi VIF değeri (Centered VIF) 10 ve üzerinde ise kuvvetli bağımlllı̆̆ın olduğu, merkezi VIF değeri 5 ve üzerinde ise kuvvetli bağımlılı̆̆ın daha hassas olduğu kabul edilebilir (Ege ve Bayrakdaroğlu, 2008: 377). Mevcut çalışma test sonuçlarına göre ise en yüksek merkezi VIF değerinin 1.005 olduğu görülmektedir. Bu sonuçlar, bir önceki analiz olan spearman korelasyon testini ve serpilme diyagramı sonuçlarını doğrular niteliktedir. Sonuç olarak bağımsız değişkenler arasında çoklu doğrusal bağlantı sorunu olmadığı yorumu yapılabilir. Çalışmanın sonraki aşamasında değişkenlerin dışşal değişkenler olup olmadığını tespit etmek için, AR karakteristik polinomun ters kök analizine geçilmiştir.

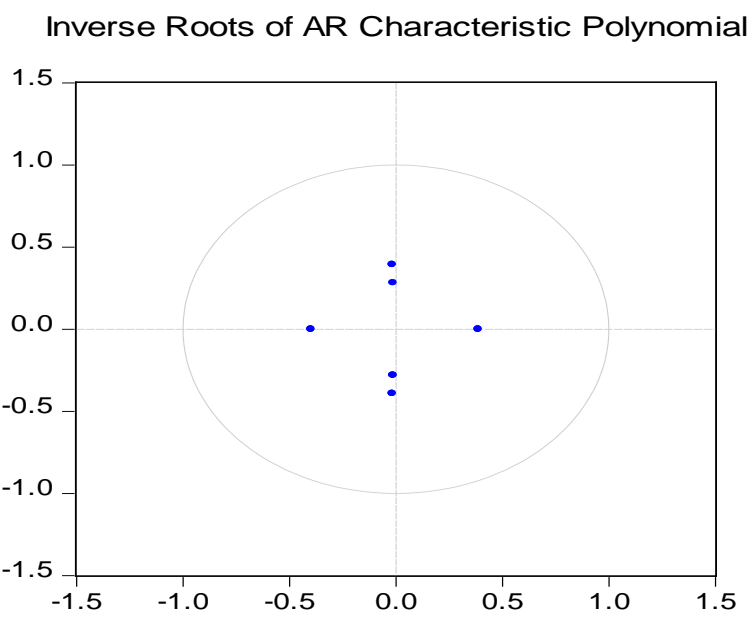

Şekil 3. AR Karakteristik Polinomun Ters Köklerinin Birim Çember İçerisindeki

Konumu

AR karakteristik polinomun ters kök analizinde kökler çember içerisinde yer alıyorsa bağımsız değişkenler için dışsal değişken değildir yorumu yapılabilir. Yani diğer bir ifadeyle; değişkenler konuyla ilgisiz değişkenler değildir yorumu yapılabilir. Yukarıda tablo 
incelendiğinde de görülecektir, modelde elde edilen köklerin tamamı çember içerisindedir. Dolayısıyla bağımsız değişkenlerin dışsal değişken olmadığı söylenebilir.

Değişken analizlerinden sonra, yatay kesit bağımlılı̆̆ı ve birim kök testleri için en uygun gecikme uzunluğunun belirlenmesi aşamasına geçilmiştir. Gecikme uzunluğunun belirlenmediği durumlarda, değişkenlerin uzunlukları daha yüksek değer alabilmekte bu da analizde aşırı parametreleşme sorunu yaratmaktadır (Bozdağlığlu ve Özpınar, 2011: 47). Gecikme uzunluğu test sonuçları aşağıda sunulmuştur;

Tablo 7. Gecikme Uzunluğunun Belirlenmesi

\begin{tabular}{ccccccc}
\hline Lag & LogL & LR & FPE & AIC & SC & HQ \\
\hline 0 & -162.4710 & NA & 0.049891 & 5.515701 & $5.620418^{*}$ & 5.556661 \\
1 & -149.1662 & 24.83575 & 0.043247 & 5.372205 & 5.791074 & $5.536048^{*}$ \\
2 & -136.9036 & $21.66386^{*}$ & $0.038892^{*}$ & $5.263453^{*}$ & 5.996474 & 5.550178 \\
3 & -134.0928 & 4.684584 & 0.048101 & 5.469761 & 6.516934 & 5.879368 \\
4 & -131.6260 & 3.864782 & 0.060497 & 5.687532 & 7.048856 & 6.220021 \\
5 & -126.6930 & 7.234977 & 0.070588 & 5.823101 & 7.498576 & 6.478471 \\
6 & -124.8082 & 2.575931 & 0.092022 & 6.060273 & 8.049900 & 6.838526 \\
7 & -123.4420 & 1.730451 & 0.123502 & 6.314735 & 8.618514 & 7.215869 \\
8 & -116.7264 & 7.834957 & 0.140740 & 6.390879 & 9.008810 & 7.414896 \\
\hline
\end{tabular}

* indicates lag order selected by the criterion

LR: sequential modified LR test statistic (each test at 5\% level)

FPE: Final prediction error

AIC: Akaike information criterion

SC: Schwarz information criterion

HQ: Hannan-Quinn information criterion

Literatürde yapılan çalışmalarda, gecikme uzunluğunun belirlenmesi aşamasında en çok ‘Akaike Bilgi Kriteri (AIC)' ve 'Schwarz Bilgi Kriteri (SC)' kullanıldı̆̆ı görülmektedir. Mevcut çalışmada gecikme uzunluğunun belirlenmesinde akaike bilgi kriteri baz alınmıştır. Tabloda yer alan test sonuçları incelendiğinde, akaike bilgi kriterine göre en uygun gecikme uzunluğunun 2 olduğu görülmektedir. Dolayısıyla mevcut çalışmanın gecikme uzunluğu 2 olarak belirlenmiştir.

Uygun gecikme uzunluğunun tespitinden sonra, yatay kesit bağımlılığı analizine geçilmiştir. Elde edilen test sonuçları aşağıda sunulmuştur; 
Panel veri analizlerinde tutarlı ve güvenilir sonuçlar elde etmek için serilerin durağan olması gerekmektedir. Çalışmada durağanlık sınaması ilk olarak LLC Panel Birim Kök testi ile sınanmıştır. Çalışmada kullanılan değişkenlere ait veriler tam ve eksiksiz olduğu için 'Balanced Örnekleme' seçilmiştir. Yukarıdaki tabloda görüldüğü gibi hem sabit modelde hem de sabit ve trend modelinde olasılık değerleri kritik değer olan 0,05 değerinin altındadır. Yani tüm serilerin durağan oldukları, birim köke sahip olmadıkları yani I(0) olduğu tespit edilmiştir.

Mevcut çalışmada tutarlı ve güvenilir sonuçlar elde edebilmek adına, bir diğer birinci nesil birim kök testi olan IPS (2003) Panel Birim Kök test sınaması da uygulanmıştır. Test sonuçları aşağıda verilmiştir;

Tablo 10. IPS (2003) Panel Birim Kök Test Sonuçları

\begin{tabular}{|c|c|c|c|c|c|}
\hline \multicolumn{6}{|c|}{ Sabit } \\
\hline & İsta. & Olas-değer & \multirow{4}{*}{ Birinci Fark } & İsta. & Olas-değer \\
\hline PAYGET & -9.50241 & 0.0000 & & & \\
\hline DOGYAT & -5.60789 & 0.0000 & & & \\
\hline PORTYAT & -5.57522 & 0.0000 & & & \\
\hline \multicolumn{6}{|c|}{ Sabit ve Trend } \\
\hline & İsta. & Olas-değer & \multirow{4}{*}{ Birinci Fark } & İsta. & Olas-değer \\
\hline PAYGET & -7.12944 & 0.0000 & & & \\
\hline DOGYAT & -4.78548 & 0.0000 & & & \\
\hline PORTYAT & -3.86922 & 0.0001 & & & \\
\hline
\end{tabular}

Not 1: IPS testinde uzun dönem tutarlı hata varyansı hesaplanırken "Kernel" tahmincisi olarak Barlett yöntemi kullanılmış ve bant genişliği "bandwith" Newey-West yöntemine göre seçilmiştir. IPS tesinde, maksimum gecikme uzunluğu 2 olarak alınmış ve optimal gecikme uzunluğu Schwarz bilgi kriterine göre belirlenmiştir.

Not 2: ***,** ve * sirasıyla $\% 1, \% 5$ ve $\% 10$ anlamlılık düzeyini göstermektedir.

Tabloda yer alan sonuçlar incelendiğinde, bir önceki test olan LLC (2001) Panel Birim Kök testi sonuçlarını destekler nitelikte olduğu görülmektedir. Hem sabit hem de sabit ve trend model için serilerin durağan olduğu yani I(0) olduğu sonucuna ulaşılmıştır.

Mevcut çalışmanın bundan sonraki aşamasında, elde edilen bulgular doğrultusunda model tahminlemesi yapılacaktır. Fakat öncesinde tahmin yönteminin belirlenmesi gerekmektedir. Literatürde model tahminlemesi için Klasik Model, Sabit Etkiler Modeli ve Rassal Etkiler Modellerinin kullanıldığı görülmektedir. Bu modellerden hangisinin kullanılacağı F, LM ve Honda Testleri analiz sonuçları kapsamında yorumlanacaktır. Elde edilen test sonuçları aşağıda sunulmuştur; 
Tablo 11. F, LM ve Honda Tahmin Modeli Belirleme Test Sonuçları

\begin{tabular}{|c|c|c|c|}
\hline \multirow{10}{*}{ PAYGET } & Test & İstatistik & Olasılık Değeri \\
\hline & F-grup & 0.494130 & 0.779777 \\
\hline & F-zaman & 7.141609 & 0.000000 \\
\hline & F-iki yönlü & 5.619236 & 0.000000 \\
\hline & LM-grup & 2.077553 & 0.149480 \\
\hline & LM-zaman & 57.85269 & 2.82E-14 \\
\hline & LM-iki yönlü & 59.93024 & $9.69 \mathrm{E}-14$ \\
\hline & Honda-grup & -1.441372 & 0.925260 \\
\hline & Honda-zaman & 7.606095 & $1.41 \mathrm{E}-14$ \\
\hline & Honda-iki yönlü & 4.359118 & 6.53E-06 \\
\hline
\end{tabular}

Yukarıdaki analizde 3 çeşit test kullanılmıştır. Bu testlerden F testi; Havuzlanmış Model ile Sabit Etkiler Modeli arasında seçim yapmamızı sağlamakta olup, LM ve Honda testleri ise Havuzlanmış Model ile Rassal Etkiler Modeli arasında seçim yapmamıza imkân tanımaktadır. Çalışmanın t boyutunun $n$ boyutundan büyük olduğu düşünülürse, buna ilaveten çalışmada ele alınan kapsam, belirli bir topluluğu (BRICS-T) ifade ettiği, çalışmanın veri setinin de belirli bir dönem aralığında ele alındığı göz önünde bulundurulursa, zaman etkisinin olduğu tek yönlü Sabit Etkiler Modeli ile tahminleme yapmanın daha tutarlı olacağı sonucuna ulaşılmaktadır. Nitekim, yukarıdaki tabloda yer alan analiz sonuçları da bu durumu destekler niteliktedir. F testinin zaman boyutu olasılık değeri, kritik değer olan 0.05 'ten küçük olduğu görülmektedir.

F testi ile tahminleme yapılmasına karar verildikten sonra, son varsayımsal sınama testleri olan otokorelasyon ve değișen varyans sorunlarına bakılmıştır. Değişen varyans testi Breusch-Pagan-Godfrey LM testi ile sinanırken, otokorelasyon problemi ise Baltagi ve Li (1991) ve Born ve Bretuing (2016) testleri ile sinanmıştır. Tüm bunlara ilaveten, otokorelasyon probleminin 1srarcılığını tespit etmek için Durbin-Watson testi de ayrıca sınanmıştır. Elde edilen sonuçlar aşağıdaki tabloda sunulmuştur; 
Tablo 12. Değişen Varyans ve Otokorelasyon Test Sonuçları

\begin{tabular}{|c|c|c|}
\hline \multicolumn{3}{|c|}{ Sabit Etkiler Modeli İçin } \\
\hline \multicolumn{3}{|c|}{ Değişen Varyans } \\
\hline Breusch-Pagan-Godfrey LM & 12.88664 & 0.024465 \\
\hline \multicolumn{3}{|c|}{ Ardışık Bağımlılık (Otokorelasyon) } \\
\hline Baltagi ve Li (1991) LMp & 9.843918 & 0.001704 \\
\hline Born ve Bretuing (2016) LMp & 14.06505 & 0.000177 \\
\hline Durbin-Watson & 2.467214 & \\
\hline
\end{tabular}

Tek yönlü Sabit Etkiler Modeli ile hesaplanmış değişen varyans ve otokorelasyon analiz sonuçları yukarıdaki tabloda incelendiğinde; Breusch-Pagan-Godfrey LM (Lagrange Multiplier Testing) testinin olasılık değeri (0.02) kritik değerden (0.05) küçüktür. Buradan hareketle sıfır hipotezi (H0: değişen varyans yoktur) reddedilmektedir. Yani yapılan panel veri analizinde değișen varyans söz konusudur. Otokorelasyon test sonuçlarına bakıldığında; hem Baltagi ve Li (1991) testi olasılık değeri hem de Born ve Bretuing (2016) testi olasılık değeri kritik değer olan 0.05 'in altındadır ve sıfır hipotezi reddedilir. Yani diğer bir ifadeyle, yapılan panel veri analizinde otokorelasyon sorunu vardır. Son olarak Durbin-Watson test sonuçlarına da bakacak olursak, test değerinin 2.467214 gibi bir değer aldığı görülmektedir. Literatürde yapılan çalışmalarda, Durbin-Watson katsayısının 2-2,5 üzerinde olması Sabit Etkiler Modeli için otokorelasyon probleminin 1srarcı/önemli olduğu, 2'den küçük bir değer alması durumunda ise 1srarc1/önemli olmadığ 1 belirtilmektedir. Dolayısıyla Durbin-Watson testine göre otokorelasyon sorununun varlığından bahsedilebilir.

Değişen varyans ve otokorelasyon sınamalarından sonra, zaman etkisinin olduğu tek yönlü Sabit Etkiler Modeli ile değișen varyans, otokorelasyon sorunlarını ve panel standart hataları çözen White Period dirençli tahmincisi ile tahminleme yapılmıştır.

Tablo 13. Tahmin Sonuçları

\begin{tabular}{|c|c|c|c|c|}
\hline Değişkenler & Katsayı & $\begin{array}{c}\text { Standart } \\
\text { Hata }\end{array}$ & t-istatistik & Olasılık \\
\hline DOGYAT & 0.062526 & 0.052133 & 1.199361 & 0.2338 \\
\hline PORTYAT & 0.016106 & 0.007942 & 2.028102 & 0.0458 \\
\hline $\mathbf{C}$ & 0.164406 & 0.010719 & 15.33835 & 0.0000 \\
\hline \multicolumn{5}{|c|}{ Effects Specification } \\
\hline $\mathbf{R}^{2}$ & 0.638765 & & Ort. Bağımlı Değ. & 0.167676 \\
\hline Düzeltilmiş $\mathbf{R}^{2}$ & 0.534312 & & Stan. Sap. Bağ. Değ. & 0.374362 \\
\hline S.H. of Regresyon & 0.255469 & & Akaike Bilgi Kri. & 0.308244 \\
\hline Resid Kare Ort. & 5.416962 & & Schwarz Bilgi Kri. & 0.929108 \\
\hline Log Likelihood & 8.354827 & & Hannan-Quinn Bil. & 0.559982 \\
\hline F-istatistik & 6.115317 & & Durbin-Watson İst. & 2.075911 \\
\hline Olasılık (F-istatistik) & 0.000000 & & & \\
\hline
\end{tabular}

Yukarıdaki tabloda yer alan tahmin sonuçları incelendiğinde; modelin bütüncül olarak anlamlılığını gösteren F-istatistik olasılık değerinin, kritik değer olan 0.05 'ten küçük olduğu görülmektedir. Buradan hareketle model anlamlı ve geçerlidir yorumu yapılabilir. Bir diğer önemli gösterge, modelin açıklama gücü olan R2'dir. Fakat analizde birden fazla bağımsız 
değişkenler yer aldığı için düzeltilmiş R2 oranına bakmamız gerekecektir. R2 oranının 0.63 , değişkenler dahil edilince düzeltilmiş R2 oranının ise 0.53 olduğu görülmektedir. Yani doğrudan yabancı yatırımlar ile portföy yatırımlarının, BRICS-T ülkeleri pay piyasa getirisindeki değişimlerin 0.53 'ünü açıklamaktadır. Tabloda yer alan bir diğer önemli gösterge değişkenlerin birbiri ile olan ilişkilerde ne tür tepkiler verdiğidir. Bağımsız değişken olan DOGYAT'in olasılık değerinin istatistiki olarak anlamlı sonuçlar vermemesinden dolayı bu değişken hakkında bir yorum yapılamamakla birlikte, bir diğer bağımsız değişken olan PORTYAT'ta bir birimlik artış pay piyasa getirisinde 0.0161 birimlik artışa yol açmaktadır. Dolayısıyla portföy yatırımları ile pay piyasası getirisi arasında pozitif bir ilişki olduğu söylenebilir. Bununla birlikte, PORTYAT değişkeninin olasılık değerinin (0.04) kritik değer olan 0.05 'ten küçük olduğu, \%95 güven düzeyinde anlamlı olduğu sonucuna ulaşılmıştır.

Elde edilen bu sonuçlardan hareketle, yukarıda hipotezler kısmında kurulmuş iki hipotezden Hipotez 1 için H0 hipotezi DOGYAT olasılık değeri kritik değerden büyük olduğu için reddedilememiştir. Yani doğrudan yabancı yatırımlar ile pay piyasa getirisi arasında anlamlı bir istatistiki ilişki yoktur. Fakat Hipotez 2 için H0 hipotezi PORTYAT olasılık değeri kritik değerden küçük olduğu için reddedilmiştir. Yani portföy yatırımları ile pay piyasa getirisi arasında anlamlı bir ilişkinin tespit edildiği söylenebilir.

\section{SONUÇ VE ÖNERILLER}

$\mathrm{Bu}$ çalışmada BRICS-T ülkelerine yapılan doğrudan yabancı yatırımlar ile portföy yatırımlarının, ülkelerin pay piyasası getirilerine etkisini incelenmiştir. $\mathrm{Bu}$ amaç doğrultusunda 2000-2018 dönem aralığından yıllık bazda ülkelere yapılan doğrudan yabancı yatırımlar ve portföy yatırımları ile yine yıllık bazda ülkelerin pay piyasalarına ait yılın son işlem günü kapanış fiyatları alınarak bir veri seti oluşturulmuş ve panel veri analiz yöntemi ile analiz edilmiştir. Doğrudan yabancı yatırımlar ve portföy yatırımların pay piyasa getirisini etkisini daha anlaşılır ifade etmek adına, bağımsız değişkenler baz alınarak iki farklı hipotez oluşturulmuştur. Bu hipotezlerden ilki olan Hipotez 1 için HO hipotezi; doğrudan yabancı yatırımlar ile pay piyasası arasında anlamlı bir ilişki olmadığı ifade ederken, Hipotez 2 için H0 hipotezi; portföy yatırımları ile pay piyasası arasında anlamlı bir ilişki olmadığını ifade etmektedir. Bu doğrultuda sırasıyla; çoklu doğrusal bağlantı ve içsellik testleri, gecikme uzunluğu testi, yatay kesit bağımlılığı, durağanlık testleri ve değişen varyans ve otokorelasyon testleri uygulanmıştır.

Yapılan testler sonucunda, çalışmada çoklu doğrusal bağlantı sorununun ve içsellik problemlerinin olmadığı, gecikme uzunluğunun 2 olarak belirlendiği, değişkenler arasında yatay kesit bağımlılığının olmadığı, serilerin seviyede durağan olduğu ve modelde değişen varyans ve otokorelasyon sorunun olduğu sonuçlarına ulaşılmıştır.

Zaman etkisinin olduğu tek yönlü sabit etkiler modeli ile değişen varyans, otokorelasyon sorunlarını ve panel standart hataları dikkate alıp çözen White Period dirençli tahmincisi ile yapılan tahminleme sonucunda ise doğrudan yabancı yatırımlar ile pay piyasası arasında istatistiki olarak anlamlı bir ilişki bulunamamış fakat portföy yatırımlarının pay piyasasını pozitif etkilediği sonucuna ulaşılmış̧ır. Elde edilen bu sonuçlar; Errunza (2001), Weiss ve Nikitin (2004), Poshakwale ve Thapa (2007), Gupta vd. (2013), Bhatia ve Kishor (2015), Raghavan ve Selvam (2017), Iriobe vd. (2018) ve Ege vd. (2019) çalışmalarılyla benzerlik göstermektedir. 
$\mathrm{Bu}$ çalışma, doğrudan yabancı yatırımlar ve portföy yatırımlarının BRICS-T ülkeleri pay piyasa getirilerine etkisini incelemesi bakımından literatürde yapılan öncü çalışmalardandır. Doğrudan yabancı yatırımların daha çok ülke ekonomilerini ilgilendiren uzun vadeli bir yatırım türü olmasından dolayı finansal piyasalara direk bir etkisi beklenmemektedir. Fakat portföy yatırımlarının ise likit bir yatırım olması ve doğrudan finansal piyasalara yapılan bir yatırım türü olmasından dolayı pay piyasalarını pozitif yönde etkilemesi beklenen bir durumdur.

$\mathrm{Bu}$ çalışma kapsamında; pay piyasalarının gelişmesi için ülkelerin şeffaf bir bürokrasi izlemeleri, hukuk devleti anlayışını benimsemeleri, maliye ve para politikalarının uyumlu bir şekilde birlikte hareket etmeleri ve ülkelerin kendi dinamikleri doğrultusunda portföy yatırımlarını çekmek için gerekli özendirici politikaları izlemeleri önerilmektedir.

\section{KAYNAKLAR}

Adam, M. Adam - Tweneboah, George (2008), 'Foreign Direct Investment and Stock Market Development: Ghana Evidence’, Munich Personal Repec Archive, 11261, pp. 1-13.

Al-Halalmeh, Mohammad - Sayah, Abedalsttar M. (2010), 'Impact of Foreign Direct Investment on Share Market Value in Amman Exchange Market', American Journal of Economics And Business Administration, 2(1), pp. 35-38.

Anayochukwu, Ozurumda Benedict (2012), 'The Impact of Stock Market Returns of Foreign Portfolio Investment in Nigeria', IOSR Journal of Business and Management, 2(4), pp. 10-19.

Aranyarat, Chonnikarn (2011), 'The Effect of Exchange Rate Volatility on Foreign Direct Investment and Portfolio Flows to Thailand', Chulalongkorn University Library, pp. $1-30$.

Bhatia, Ankita - Kishor, Naval (2015), 'Linkages of Foreign Portfolio Investments and Stock Market Indices: Evidence from BRICS Nations', Journal of Poverty Investment and Development, 19, pp. 1-21.

Bozdağlığlu, E. Yasemin - Özpınar, Ömer (2011), 'Türkiye’ye Gelen Doğrudan Yabancı Yatırımların Türkiye'nin İhracat Performansına Etkilerinin VAR Yöntemi ile Tahmini’, Dokuz Eylül Üniversitesi Sosyal Bilimler Enstitüsü Dergisi, 13(3), ss. 3963.

Das, Dilip K. (2000), 'Portfolio Investment in Emerging Market Economies: Trends, Dimensions And Issues’, Journal of Asset Management, 1, pp. 172-195.

Ege, İlhan - Bayrakdaroğlu, Ali (2008), 'Sermaye Yapısının Cari Değer ve Verimlilik Üzerine Etkisi: Türk Sigortacıllk Sektöründe Bir Uygulama’, Atatürk Üniversitesi İktisadi ve İdari Bilimler Dergisi, 22(2), ss. 379-395.

Ege, İlhan - Şahin, Serkan - Topaloğlu, Emre Esat (2019), 'The effect of Foreign Direct and Portfolio Invesments on Stock Market Returns in E7 Countries. Muhasebe ve Finansman Dergisi, 83, pp. 263-178. 
Errunza, Vihang (2001), 'Foreign Portfolio Equity Investments Financial Liberalization and Economic Development', Review of International Economics, 9(4), pp. 703-726.

Felek, Şencan (2016), Türkiye'de AB Doğrudan Yatırımları, Finansal Gelişme ve Ekonomik Büyüme İlişkisinin Ekonometrik Analizi, Pamukkale Üniversitesi Sosyal Bilimler Enstitüsü İktisat Anabilim Dalı Yüksek Lisans Tezi.

Göçer, İsmet - Mercan, Mehmet - Hotunluoğlu, Hakan (2012), 'Seçilmiş OECD Ülkelerinde Cari Işlemler Açığının Sürdürülebilirliği: Yatay Kesit Bağımlılığı Altında Çoklu Yapısal Kırılmalı Panel Veri Analizi’, Maliye Dergisi, 163, ss. 449-467.

Guerin, Selen Sarısoy (2006), 'The Role of Geography in Financial and Economic Integration: A Comparative Analysis of Foreign Direct Investment Trade and Portfolio Investment Flows', Journal Compilation, 29(2), pp. 189-209.

Gupta, Shaveta - Kalra, Neha - Bagga, Rajesh (2013), 'Impact of Foreign Investments on Stock Market Volatility: An Evidence from Indian Stock Market', Effective Management, pp. 1-13.

Halale, Mahesh (2014), 'Influence of Foreign Portfolio Investment on Stock Market Indicators', International Journal of Management, 5(10), pp. 1-11.

Hermes, Niels - Lensink, Robert (2003), 'Foreign Direct Investment Financial Development and Economic Growth', The Journal of Development Studies, 40(1), pp. 142-163.

Idenyi, Odo Stephen - Ifeyinwa, Anoka Charity - Obinna, Nwachukwu Johnson - Promise, E. Agbi (2016), 'Impact of Foreign Direct Investment on Stock Market Growth in Nigeria', Asian Research Journal of Arts \& Social Sciences, 1(2), pp. 1-14.

Iriobe, Grace O. - Obamuyi, Tomola Marshal - Abayomi, Muftau A. (2018), 'Effect of Foreign Portfolio Investment in Bond Stocks on The Performance of the Nigerian Stock Market', Archives of Business Research, 6(12), pp. 164-172.

Islam, Mollah Aminul - Khan, Muhammed Asif - Popp, Jozsef - Sroka, Wlodzimiers - Olah, Judith (2020), 'Financial Development and Foreign Direct Investment - The Moderating Role of Quality Institutions', Sustainability, 12, pp. 1-22.

Kim, Woochan - Wei, Shang Jin (2002), 'Foreign Portfolio Investors Before and During A Crisis', Journal of International Economics, 56, pp. 77-96.

Poshakwale, Sunil - Thapa, Chandra (2007), 'Impact of Foreign Portfolio İnvestments on Market Comovements: Evidence from The Emerging Indian Stock Market', Emerging Market Group ESRC Seminar on International Equity Markets Comovements and Contagion, 10, pp. 1-26.

Raghavan, S - Selvam, Marudhamuthu (2017), 'Determinants of Foreign Portfolio Investment and Their Effects on the Indian Stock Market', International Journal of Management, 8(3), pp. 105-115. 
Somuncu, Kartal - Karan, Mehmet Baha (2005), 'The Impact of International Portfolio Investments on Istanbul Stock Exchange Market', Sayıştay Dergisi, 77, pp. 149-167.

Vita, Glauco De - Kyaw, Khine S. (2009), 'Growth Effects of FDI and Portfolio Investment Flows to Developing Countries: A Disaggregated Analysis By Income Levels', Applied Economics Letters, 16, pp. 277-283.

Weiss, Andrew - Nikitin, Georgiy A. (2004), 'Foreign Portfolio Investment Improves Performance: Evidence From The Czech Republic', Topics in Economic Analysis \& Policy, 4(1), pp. 1-47.

www.investing.com, (02.03.2020).

www.worldbank.org, (01.03.2020). 
